\title{
Preparation and Characterization of Chitosan Silicate Conjugate: It's Role as a Super Disintegrant in Orally Fast Dissolving Films
}

\author{
Satheesha Babu Birur Kotappa ${ }^{1, *}$, Podamala Rama Smriti ${ }^{2}$ \\ ${ }^{1}$ Department of Pharmaceutics, Government College of Pharmacy, \#2, P Kalinga Rao Road, Subbaiah Circle, Bengaluru, \\ Karnataka, INDIA. \\ ${ }^{2}$ Associate Clinical Publisher at M/S Nova Nordic Service Centre india Private Ltd, Bengaluru, Karnataka, INDIA.
}

\begin{abstract}
Aim: The aims of the present research work was to prepare and characterize the chitosan silicate conjugate, conjugate was included in orally fast dissolving films of levo cetirizine di hydrochloride as a super disintegrant and to compare disintegration efficiency with commercial super disintegrant. Materials and Methods: Conjugate was prepared by reacting chitosan with colloidal silicon dioxide. Characterized primarily by determining the charring point, viscosity and wicking property confirmed by Fourier transforms infrared spectroscopy, differential scanning calorimetry and X-ray powder diffraction analysis. The compatibility between the drug excipients was confirmed by Fourier transforms infrared spectroscopy and differential scanning calorimetry. Orally fast dissolving films were prepared by solvent casting technique by using hydroxypropyl methylcellulose E15, polyethylene glycol 400 as the plasticizer, conjugate and crospovidone as super disintegrants. The films were subjected to post-formulation parameters by determining weight variation, thickness, swelling index, folding endurance, tensile strength, percentage elongation, drug content, drug content uniformity, in vitro disintegration time, in vitro dissolution study, in vitro permeation study, surface morphology and accelerated stability studies. Results: The results of characterization of prepared conjugate revealed that conjugation took place. Compatibility study suggested that drug and excipients were compatible. The prepared films were having smooth surface, drug was uniformly distributed, had good physical and tensile strength. The film consists of $100 \mathrm{mg}$ of conjugate as super disintegrant took less time for disintegration as compared with 100 mg of commercial super disintegrant. Conclusion: By considering the results of the present study may be concluded that the disintegration capacity of prepared conjugate was high compared to commercial disintegrant.
\end{abstract}

Key words: Orally fast dissolving films, Chitosan silicate conjugate, Super disintegrant, Disintegration time, in vitro dissolution, in vitro permeation, Reversed phase-high performance Liquid chromatography.

\section{INTRODUCTION}

In emergency treatment of certain disorders like angina, emesis, allergy and asthma where quick onset of action is required for immediate relief to the patients, because of this in the present study an attempt was made to prepare orally fast dissolving films (OFDF) of levo cetirizine di hydrochloride. The conventional oral dosage forms are having limitations to suit such situations. The primary objectives of the present research study were preparation and characterization of chitosan silicate conjugate (CSC) and it's suitability as super disintegrant. The disintegration capacity of CSC was compared with commercially available super disintegrant crosprovidone. The above objectives can be achieved by formulating suitable drugs in fast dissolving oral films (OFDF). OFDF are very thin films and undergo instant wetting
Submission Date: 29-05-2020; Revision Date: 25-08-2020; Accepted Date: 14-04-2021

DOI: 10.5530/ijper.55.2s.110 Correspondence:

Prof. Satheesha Babu Birur Kotappa

Department of Pharmaceutics, Government College of Pharmacy, Rajiv Gandhi University of Health Sciences, Bengaluru-560027, Karnataka, INDIA.

Phone: +91-9481687878 Email id: bksatishbabu@ gmail.com

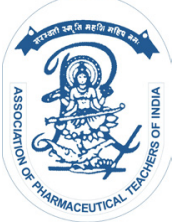

www.ijper.org 
by the saliva resulting in immediate dissolve within a few seconds when they are placed below the tongue and facilitate quick or mucosal absorption through sublingual route avoiding fast pass metabolism thereby enhancing the bioavailability. ${ }^{1}$ Apart from this advantage OFDF have other advantages, in emergency conditions and during travelling they allow patients to consume formulations without a water, conveniently administer the formulations to pediatric, geriatric, bed ridden and psychiatric patients and these formulations offers no risk of chocking. The films having a larger surface area, quick wetting followed by faster disintegration and dissolution in oral cavity makes them better than orally fast dissolving tablets. Along with these several advantages OFDF has few disadvantages it includes incorporation of larger doses are not possible, a special type of package is needed since most of the excipients are highly hygroscopic in nature and drugs unstable in oral cavity $\mathrm{pH}$ and causes the irritation of oral mucosa are not suitable. ${ }^{2,3}$

Allergic rhinitis or hay fever is the disease manifested by inflammation of the mucus membrane of nose due to pollen, pet hair, dust or mold leads to overreaction of immune system with these allergens in the air there by $\operatorname{IgE}$ antibodies attaching to the allergen initiate the release of inflammatory autacoid histamine from must cells results in histamine mediated hypersensitive reaction with symptoms of sneezing, blocked of nose and watering eyes. Urticarial is an allergic condition due to hypersensitivity to food, drug, infection, physical agents such as heat, cold and light or emotional stress. This is manifested by appearance of slightly elevated patches or wheals with red or paler than the surrounding skin accompanied by sever itching on the skin. These allergic conditions are due to vasodilation and increased permeability of the capillaries of the skin due to $\operatorname{IgE}$ mediated sensitivity reaction with the allergen resulted in release of histamine from the mast cell. ${ }^{4}$ These allergic manifestations has to be treated immediately otherwise they may lead to other serious complications, Levo cetirizine di hydrochloride is a selective, potent, active and a long acting third generation, non-sedative antihistaminic drug ${ }^{5}$ and drug of choice in such allergic complications. For immediate therapeutic response and onset of action Levo cetirizine di hydrochloride is formulated as OFDF.

Chitosan is a linear polysaccharide derived from the de acetylation of chitin, a naturally abundant organic material obtained mainly from the exoskeleton of the crustaceans (Lobsters, shrimps and crabs) and insects as well as from the cell walls of some bacteria and fungi. Chemically chitosan is composed of glucosamine and
$\mathrm{N}$-acetyl glucosamine units linked by (1-4) glycosidic bonds. ${ }^{6}$ In the present study an effort was made to synthesis and characterize the chitosan silicate conjugate to be used as a novel super disintegrant. The disintegration capacity of chitosan silicate conjugate was compared with commercially available super disintegrant.

\section{MATERIALS AND METHODS}

\section{Materials}

Levo cetirizine dihydrochloride and aspartame were received as a gift sample from Karnataka Antibiotics and Pharmaceuticals Ltd. Bengaluru, India. Crospovidone was gifted by Strides Arco Laboratories ltd, Bengaluru, India. Chitosan was purchased from Himedia Labs Pvt. Ltd., Mumbai, India. All other chemicals and solvents used were of analytical grade.

\section{Methods}

\section{Preparation of chitosan silicate conjugate}

About $1 \mathrm{~g}$ of chitosan was suspended in $35 \mathrm{ml}$ of $2 \mathrm{M}$ $\mathrm{HCl}$ and approximately, $1 \mathrm{~g}$ of colloidal silicon dioxide was suspended in $35 \mathrm{ml}$ of $1 \mathrm{M} \mathrm{NaOH}$ solution, to which $35 \mathrm{ml}$ of deionized water was added under stirring until homogenization of the silica suspension was accomplished. The silica suspension was heated up to $80^{\circ} \mathrm{C}$ under stirring until a clear solution was obtained owing to the conversion of the insoluble suspended silicon dioxide into the soluble sodium silicate form. The chitosan suspension was gradually added to the silica suspension at room temperature, under vigorous stirring, which was continued for $1 \mathrm{~h}$ and the product was filtered. The filtrate was clear, as chitosan and/or silica particles cause turbidity when present. The product was dried at $70^{\circ} \mathrm{C}$ for overnight. ${ }^{7}$ Chitosan silicate conjugate (CSC) was stored in a well-sealed container for further characterization.

\section{Characterization of the prepared chitosan silicate conjugateCharring point}

The charring point of chitosan and chitosan silicate conjugate (CSC) was determined by transferring approximately $5 \mathrm{mg}$ of sample in a glass capillary tube sealed at one end. The sample containing capillary tube was placed in the melting point apparatus ${ }^{8}$ and the temperature was increased gradually. The temperature at which the sample charred completely was noted down as the charring point of that sample in degree centigrade.

\section{Viscosity}

Viscosity of $2 \%$ solutions of chitosan and chitosan silicate conjugate was determined by Brookfield LV 
DV-II+ Pro viscometer. Rheocalc V 2.7 software was used for this instrument. The spindle used was LV-4 (spindle number 64), which was fixed to the viscometer and the polymer solution was placed such that the spindle was completely immersed up to the mark. The spindle was run at $100 \mathrm{rpm}$ for $15 \mathrm{~s}^{9}$ and the viscosity displayed automatically on the dial was noted.

\section{Wicking study}

$0.122 \mathrm{~g}$ of chitosan and CSC was placed in each tube made of semi permeable membrane and packed with $5 \mathrm{~g}$ load. The initial weight of both the packed tubes was noted and then placed in the groves cut in the agar gel plate consists of $2 \%(\mathrm{w} / \mathrm{v})$ of agar. After every hour the increase in the weights for both the tubes was determined until constant weight was observed. ${ }^{10}$

\section{Fourier transforms infrared spectroscopy (FT-IR)}

To characterize the prepared chitosan silicate conjugate was subjected for FT-IR analysis. In present analysis the potassium bromide disc method was employed as a sample technique. The discs were prepared after thorough mixing of CSC with dry powder of potassium bromide and properly blended mixture was then subjected to compression in hydraulic pressure press for chitosan same procedure was repeated. The prepared discs were placed in the disc holder of spectrometer and spectrum was from $4000 \mathrm{~cm}^{-1}$ to $400 \mathrm{~cm}^{-1}$ by Shimadzu FT-IR 8400 spectrophotometer and the spectra's obtained were compared. ${ }^{8}$

\section{Differential scanning calorimetric analysis (DSC)}

Samples of about 1-3 mg of chitosan and CSC were used for DSC analysis by Shimadzu, DSC-60 plus instrument. Thermal behavior of samples was investigated using nitrogen as purging gas at scanning rate of $10^{\circ} \mathrm{C} / \mathrm{m},{ }^{8}$ covering the temperature range of $30-350^{\circ} \mathrm{C}$.

\section{X-ray diffraction (XRD)}

X-ray powder diffraction was obtained at room temperature $\left(25^{\circ} \mathrm{C}\right)$ using Bruker XS D8 advance diffractometer ${ }^{11}$ and the data was collected at a wide angle $5^{\circ}$ to $85^{\circ} / 2 \theta$.

\section{Compatibility studies}

Compatibility between the drug, polymer and excipients were studied by both FT-IR and DSC studies.

\section{Fourier transforms infrared spectroscopy (FT-IR)}

Potassium bromide discs consists of pure drug and the physical mixture of drug and the excipients were prepared as described in the characterization of CSC section for FT-IR analysis and subjected for scanning from $4000 \mathrm{~cm}^{-1}$ to $400 \mathrm{~cm}^{-1}$ by Shimadzu FT-IR 8400 spectrophotometer and the spectra's obtained were compared. ${ }^{12}$

\section{Differential scanning calorimetric analysis (DSC)}

Sample of about 1-3 $\mathrm{mg}$ of pure drug and the physical mixture of drug, CSC and HPMC E15 about 1-3 mg were used for DSC analysis by Shimadzu, DSC-60 plus instrument. Thermal behavior of samples was investigated using nitrogen as purging gas at scanning rate of $10^{\circ} \mathrm{C} / \mathrm{m},{ }^{12}$ covering the temperature range of $30-350^{\circ} \mathrm{C}$.

\section{Formulation of orally fast dissolving films}

Orally fast dissolving films of levo cetirizine di hydrochloride $\left(\mathrm{F}_{1}\right.$ to $\left.\mathrm{F}_{7}\right)$ were prepared by solvent casting technique ${ }^{12}$ and the formulation details are mentioned in Table 1. The film former, HPMC E15 was soaked in 10 $\mathrm{ml}$ of distilled water for $8 \mathrm{~h}$. Levo cetirizine di hydro chloride was dissolved in $5 \mathrm{ml}$ distilled water and added to the HPMC E15 solution. Chitosan silicate conjugate was dissolved in $5 \mathrm{ml}$ of $4 \%$ glacial acetic acid and added

\begin{tabular}{|c|c|c|c|c|c|c|c|c|}
\hline \multicolumn{7}{|c|}{ Table 1: Formulation Table. } \\
\hline SI.No & Ingredients & $\mathbf{F}_{\mathbf{1}}$ & $\mathbf{F}_{\mathbf{2}}$ & $\mathbf{F}_{\mathbf{3}}$ & $\mathbf{F}_{\mathbf{4}}$ & $\mathbf{F}_{\mathbf{5}}$ & $\mathbf{F}_{\mathbf{6}}$ & $\mathbf{F}_{\mathbf{7}}$ \\
\hline 1 & $\begin{array}{c}\text { Levocetirizinedihydrochloride } \\
(\mathrm{g})\end{array}$ & 0.0591 & 0.0591 & 0.0591 & 0.0591 & 0.0591 & 0.0591 & 0.0591 \\
\hline 2 & HPMC E15 (g) & 0.4 & 0.4 & 0.4 & 0.4 & 0.4 & 0.4 & 0.4 \\
\hline 3 & Crospovidone (g) & - & 0.1 & - & - & - & - & - \\
\hline 4 & CSC (g) & - & - & 0.05 & 0.1 & 0.15 & 0.2 & 0.5 \\
\hline 5 & PEG 400 (g) & 0.04 & 0.04 & 0.04 & 0.04 & 0.04 & 0.04 & 0.04 \\
\hline 6 & Aspartame (g) & 0.02 & 0.02 & 0.02 & 0.02 & 0.02 & 0.02 & 0.02 \\
\hline 7 & Citric Acid $(\mathrm{g})$ & 0.06 & 0.06 & 0.06 & 0.06 & 0.06 & 0.06 & 0.06 \\
\hline 8 & Distilled water $(\mathrm{ml})$ & 15 & 15 & 15 & 15 & 15 & 15 & 15 \\
\hline
\end{tabular}


to the above solution stirred on a magnetic stirrer at 50 rpm until a uniform dispersion is obtained. PEG 400 as the plasticizer, aspartame as the sweetener and citric acid as the salivary stimulant was added to the dispersion. The resultant mixture was continued to be stirred for $10 \mathrm{~min}$. The dispersion was poured into a glass mold of 73.86 $\mathrm{cm}^{2}$ area and allowed to dry in a hot air oven at $45^{\circ} \mathrm{C}$ for $15 \mathrm{~h}$. The resultant circular films were peeled and cut into square films of $6.25 \mathrm{~cm}^{2}$ area which consists of $5 \mathrm{mg}$ of levo cetirizine di hydrochloride per film. These square films were used for evaluation.

Evaluation of orally fast dissolving films (Postformulation parameters)

\section{Weight variation}

Films of each formulation were weighed on a Shimadzu digital balance to determine the weight variation. ${ }^{12}$

\section{Thickness}

Thickness of 6 films of each formulation was measured at four different corners and center using a screw gauge. ${ }^{12}$

\section{Swelling index}

Films of each formulation were weighed accurately and placed on agar gel plate consists of $2 \%(\mathrm{w} / \mathrm{v})$ of agar. Individual films were weighed after every $15 \mathrm{~s}$ until they disintegrated. ${ }^{8}$ Swelling index was calculated by the formula (final weight-initial weight) $/$ initial weight $\times 100$.

\section{Folding endurance}

The folding endurance of each film was measured by a modified USP tablet disintegrating test apparatus which consists of lower fixed jaw and an upper movable jaw moving at the rate of 30 strokes $/ \mathrm{m} .{ }^{8}$ The distance between the two jaws at their farthest and closest was 5 $\mathrm{cm}$ and $0.5 \mathrm{~cm}$ respectively. The films of $5 \times 1 \mathrm{~cm}$ were clamped between these two jaws, so that at closest the membrane bends at the middle and at farthest it slightly stretches and completes a cycle. The number of folds required to break the film or develop visible cracks is noted as its folding endurance.

\section{Tensile strength and percentage elongation}

The $5 \times 1 \mathrm{~cm}$ size films from each formulation were used for measurement of tensile strength and percentage elongation by Hounsfield (H1KS) tensile strength instrument consists of two load cell jaws, the lower one is movable and the upper one was fixed. The film was fixed between these grips and the lower jaw was moved, applying force gradually till the film breaks. The tensile strength of the films was taken directly from the dial reading of the instrument. The percentage elongation ${ }^{12}$ was calculated by the following formula (final lengthinitial length)/initial length $\times 100$.

\section{Percentage moisture content}

Films of each formulation were weighed individually and stored in a desiccator consists of fused calcium chloride at room temperature. Individual films were weighed at $24 \mathrm{~h}$ intervals until they showed a constant weight. ${ }^{8}$ The percentage of moisture content was calculated by the following formula (initial weight-final weight)/final weight $\times 100$.

\section{Percentage moisture uptake}

Films of each formulation was placed in the desiccator consists of saturated solution of potassium chloride, to maintain a relative humidity of $84 \%{ }^{8}$ After every 24 $\mathrm{h}$ the films were taken and weighed to determine the percentage moisture uptake by the following formula (final weight-initial weight)/initial weight $\times 100$.

\section{Water vapor transmission study}

Three $1.1304 \mathrm{~cm}^{2}$ films of each formulation were fixed over the brim of glass vial, consists of approximately 2 $\mathrm{g}$ of fused calcium chloride as desiccant. The vial was weighed and kept in a desiccator consists of saturated solution of potassium chloride to provide a relative humidity of $84 \%$. The vial was taken out and weighed at every $24 \mathrm{~h}$ interval for 7 days. The flux that is the amount of water vapor transmitted through $1 \mathrm{~cm}^{2} / 24$ h was determined. ${ }^{8}$ Graph of flux v/s time is plotted and its slope determined. The permeability coefficient was calculated by the following formula (slope/vapor pressure of saturated solution of potassium chloride).

\section{Drug content uniformity}

$6.25 \mathrm{~cm}^{2}$ film of each formulation was dissolved in 100 $\mathrm{ml}$ of water (HPLC grade), by stirring on a magnetic stirrer at $50 \mathrm{rpm}$ for $20 \mathrm{~min} .4 \mathrm{ml}$ of this solution was diluted to $10 \mathrm{ml}$ using the mobile phase and the drug content was measured by RP-HPLC. ${ }^{11}$

\section{In-vitro disintegration time}

To determine the disintegration time petri dish method ${ }^{13}$ was adopted in the present study. Films of each formulation were placed in a petri dish containing $15 \mathrm{ml}$ of phosphate buffer solution $\mathrm{pH} 6.8$ and time required for complete dissolution of films were recorded as disintegration time. The experiment was conducted in triplicate. $^{12}$

\section{In-vitro dissolution study}

An in vitro dissolution study of films was performed for $5 \mathrm{~min}$ in USP paddle apparatus using $900 \mathrm{ml}$ 
phosphate buffer solution $\mathrm{pH} 6.8$ as the dissolution media. The temperature of the dissolution medium was maintained at $37^{\circ} \mathrm{C} \pm 0.5^{\circ} \mathrm{C}$ and stirred at $100 \mathrm{rpm}$. The $5 \mathrm{ml}$ aliquots were withdrawn after first, third and fifth min and replaced with fresh phosphate buffer $\mathrm{pH}$ 6.8. The aliquots were suitably diluted with the mobile phase and the concentration of the drug was measured by RP-HPLC. ${ }^{11}$ The average peak area for each time interval was used to determine the $\% \mathrm{CDR}$ (percentage cumulative drug release).

\section{In-vitro permeation study}

The in vitro permeation experiment was conducted in a modified Franz diffusion cell with receptor compartment capacity of $16 \mathrm{ml}$ and surface area of $0.785 \mathrm{~cm}^{2}$. The diffusion cell consists of two compartments. The upper compartment is the donor compartment, consists of the film in contact with the semipermeable parchment membrane. The bottom compartment consists of the receptor compartment, the water jacket for temperature control and the sampling port. $^{8}$ The receptor compartment was filled with $16 \mathrm{ml}$ of phosphate buffer $\mathrm{pH}$ 6.8. The donor compartment was then placed in position such that the surface of the film just touches the receptor fluid surface. The whole assembly was placed on a magnetic stirrer and the solution in the receptor compartment was constantly and continuously stirred at $50 \mathrm{rpm}$. The temperature of the whole assembly was maintained at $37^{\circ} \mathrm{C} \pm 0.5^{\circ} \mathrm{C}$ by circulating hot water inside the water jacket. Samples of $1 \mathrm{ml}$ was withdrawn at first, third, fifth, seventh and ninth min from the receptor compartment and replenished with phosphate buffer solution $\mathrm{pH} 6.8$ each time. The aliquots were suitably diluted with the mobile phase and the concentration of the drug was measured by RP-HPLC. ${ }^{11}$ The average peak area for each time interval was used to determine the \% CDR.

\section{Surface morphology}

The scanning electron microscopic (SEM) images were used to determine the surface characteristics of films. The SEM images were obtained by placing the films on the double adhesive tape ${ }^{11}$ glued on an aluminum stub. These stubs were coated with gold using a sputter coater under high vacuum and high voltage to achieve a coating thickness of $30 \mathrm{~nm}$. The gold coated samples were imaged using a $3 \mathrm{kV}$ electron beam.

\section{Accelerated stability studies}

The $\mathrm{F}_{4}$ formulation was subjected for 2 month stability study according to ICH guidelines. The film was packed in self-sealing cover and stored at $40^{\circ} \mathrm{C} \pm 2^{\circ} \mathrm{C}$ and $75 \% \pm 5 \% \mathrm{RH}$ for 60 days. The films were evaluated for in vitro disintegration time, drug content and in vitro dissolution studies. ${ }^{8}$

\section{Analytical method (HPLC)}

The Shimadzu (Prominence) RP-HPLC (reversed phase high performance liquid chromatography) instrument equipped with LC-20 AT pump, SIL-20A auto sampler, SPD-20A U.V/Visible detector and Cosmicsil $C_{18}$ analytical column $(250 \mathrm{~mm} \times 4.6 \mathrm{~mm}$ inner diameter, 5 $\mu \mathrm{m}$ particle size) was used. Acetonitrile: water in the ratio 60:40 was used as the mobile phase. The mobile phase was filtered through $0.45 \mu \mathrm{m}$ membrane filter (Millipore Pvt. Ltd., Bengaluru, India) and degassed by ultrasonication before use. The flow rate was maintained at $1 \mathrm{ml} / \mathrm{m}$ and the injection volume was $20 \mu \mathrm{l}$. The peaks were detected at $230 \mathrm{~nm} \cdot{ }^{14,15}$

\section{RESULTS AND DISCUSSION}

The significant differences in charring point, viscosity and weight gain between chitosan and chitosan silicate conjugate might be due to the conjugation of chitosan and results were tabulated in Table 2. The fourier transforms infrared spectra of chitosan silicate conjugate showed sharp peak at $459.06 \mathrm{~cm}^{-1}$ indicating O-Si-O (bend) which was absent in chitosan. Chitosan showed a sharp peak at $3537.10 \mathrm{~cm}^{-1}$ indicating presence of $\mathrm{OH}$ (non-hydrogen bonded) group, absent in chitosan silicate conjugate (Figure 1). This confirms that the conjugation has occurred at the hydroxyl group linkage. The differential scanning calorimetric thermo grams of chitosan and chitosan silicate conjugate showed distinct endothermic peaks at $275.14^{\circ} \mathrm{C}$ and $101.18^{\circ} \mathrm{C}$ respectively (Figure 2), further confirms that conjugation of chitosan has taken place. The X-ray diffraction analysis of pure chitosan showed broad reflections at $9^{\circ}$ and $20^{\circ} 0$ while chitosan silicate conjugate showed sharp narrow diffraction peaks at $32^{\circ}, 46^{\circ}$ and $76^{\circ}$ (Figure 3) suggested that micro crystals were present in chitosan silicate conjugate which were absent in chitosan. This observation also is due to conjugation between chitosan and colloidal silicon dioxide.

The fourier transforms infrared spectra of drug, the physical mixture of drug and the excipients (Figure 4) showed the presence of a peak at $756.10 \mathrm{~cm}^{-1}$ indicating $\mathrm{C}-\mathrm{Cl}$ bond and at $1317.38 \mathrm{~cm}^{-1}$ indicating the $\mathrm{C}-\mathrm{N}$ bond which were the principle peaks of levo cetirizine di hydrochloride. There was no significant change in the position of the principal peaks of the drug in the physical mixture of drug and the excipients, confirms that there was no interaction between the drug and all the excipients and thus they were compatible with each 


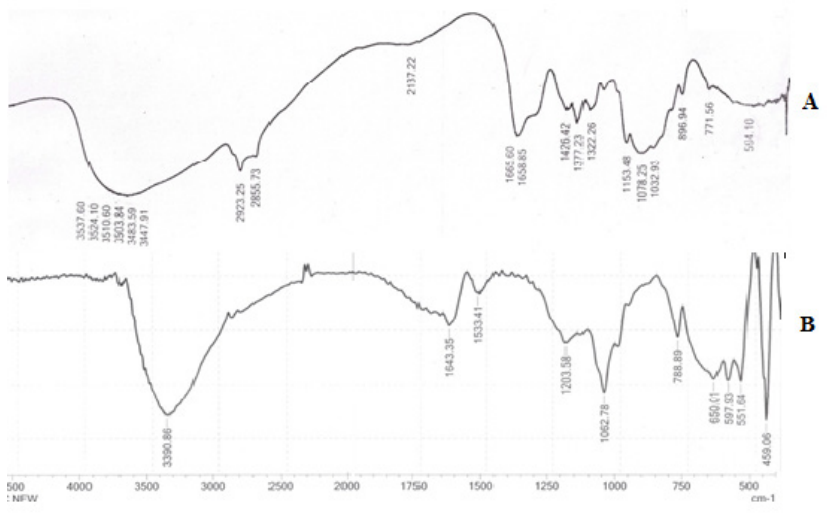

Figure 1: FT-IR spectra of chitosan (A) and CSC (B).

other. The differential scanning calorimetric thermo gram of levo cetirizine di hydrochloride showed a sharp endothermic peak at $218.81^{\circ} \mathrm{C}$ corresponding to its melting point of $217^{\circ} \mathrm{C}-220^{\circ} \mathrm{C}$ attributing to the purity of the drug (Figure 5). The differential scanning calorimetric thermo gram of the physical mixture of levo cetirizine di hydrochloride, chitosan silicate conjugate and HPMC E15 showed negligible change in the melting point of levo cetirizine di hydrochloride, as its peak was at $204.65^{\circ} \mathrm{C}$ and that of CSC and HPMC E15 was at

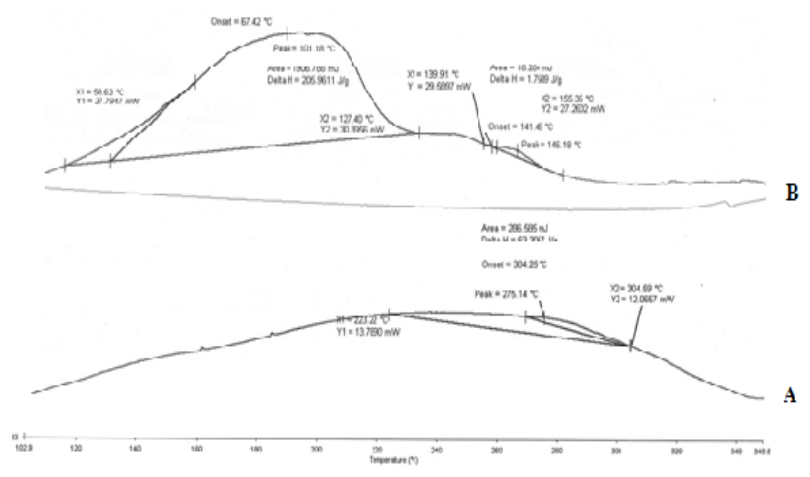

Figure 2: DSC thermogram of chitosan (A) and CSC (B).

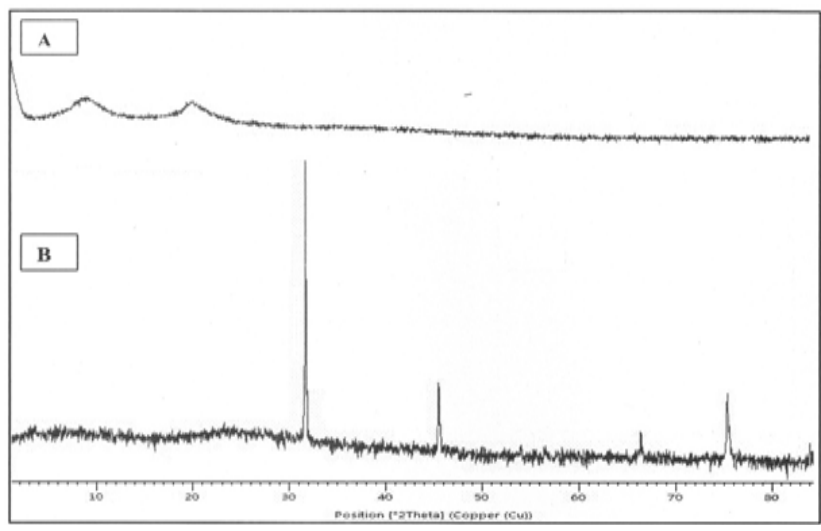

Figure 3: XRD spectra of chitosan (A) and CSC (B). $69.36^{\circ} \mathrm{C}$ and $139.88^{\circ} \mathrm{C}$ respectively. This negligible change in the peak value of the drug also suggested that the drug is compatible with the excipients.

Orally fast dissolving films of levo cetirizine di hydrochloride were prepared by solvent casting technique. There was a progressive change in the appearance of these films from transparent to opaque with increasing proportions of chitosan silicate conjugate. There was no uniform distribution of the conjugate in the films consists of maximum proportion of chitosan silicate conjugate as they were difficult to be peeled from the

\begin{tabular}{|c|c|c|c|}
\hline \multicolumn{3}{|c|}{ Table 2: Comparative Characterization of Chitosan } \\
and Chitosan Silicate Conjugate. \\
\hline SI.No & $\begin{array}{c}\text { Characterization } \\
\text { parameters }\end{array}$ & Chitosan & $\begin{array}{c}\text { Chitosan silicate } \\
\text { conjugate }\end{array}$ \\
\hline 1 & $\begin{array}{c}\text { Charring point } \\
\left({ }^{\circ} \mathrm{C}\right)\end{array}$ & $240-242$ & $135-138$ \\
\hline 2 & Viscosity (cps) & 2639 & 12 \\
\hline 3 & $\begin{array}{c}\text { Weight gain by } \\
\text { wicking (g) }\end{array}$ & 0.293 & 0.356 \\
\hline
\end{tabular}

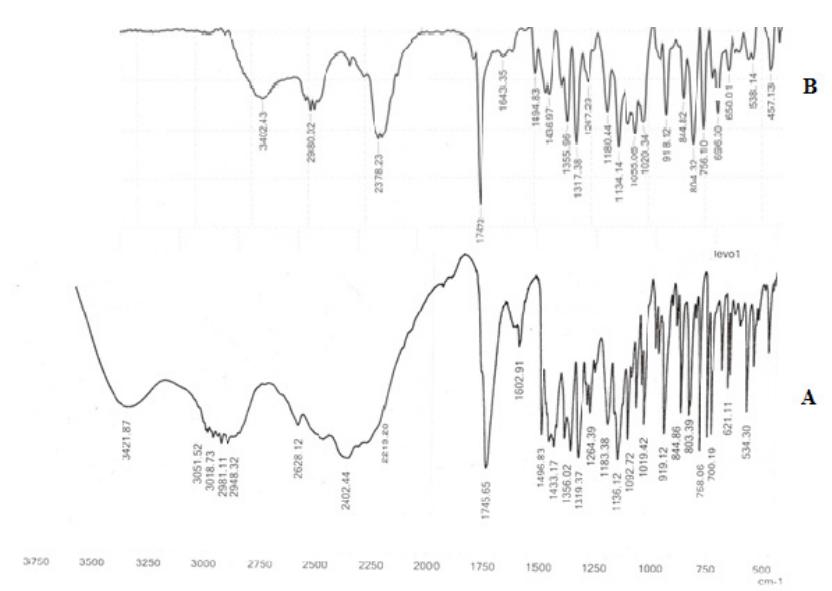

Figure 4: FTIR spectra of pure drug (A) and physical mixture of drug and excipients (B).

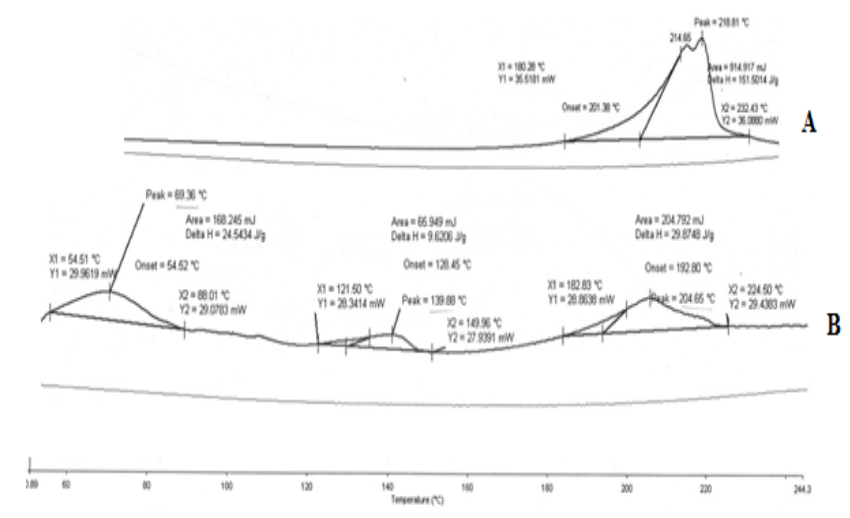

Figure 5: DSC of levocetirizine dihydrochloride (A) and physical mixture of CSC, HPMC E15 and drug (B). 
petri plate due to the micro crystallinity of chitosan silicate conjugate.

The weight and thickness of the films increased with increase in proportion of chitosan silicate conjugate and was uniform among the films of each formulation with minimal variation and results were depicted in Table 3. It was observed that $\mathrm{F}_{4}$ consists of chitosan silicate conjugate in 4:1 ratio of polymer:super Disintegrant had maximum swelling index followed by the films consists of crospovidone and a minimum for the film without chitosan silicate conjugate and results were depicted in Table 3. This suggests that chitosan silicate conjugate and crospovidone aided in the swelling of the film. Folding endurance was found to decrease with an increase in the proportion of chitosan silicate conjugate as shown in Table 3. This was due to the micro crystalline nature of chitosan silicate conjugate, confirmed by its X-ray diffraction analysis and scanning electron microscopic analysis of the films containing conjugate (Figure 6), which was responsible for the increased in fragility of the films with an increase in its proportion. The folding endurance of films with crospovidone (commercially used super disintegrant) was the highest and those consists of the same proportion of chitosan silicate conjugate was also good, suggested that the films would not break during stress conditions like folding and stretching. Due to the microcrystalline nature of chitosan silicate conjugate, tensile strength and percentage elongation of films was found to decrease with increase in proportion of chitosan silicate conjugate and same observation was made in folding endurance test results were depicted in Table 3. High tensile strength and percentage elongation of $\mathrm{F}_{4}$ consists of chitosan silicate conjugate in 4:1 ratio of polymer: super disintegrant and films with crospovidone in the same ratio, suggest that these films have a good ability to withstand stress and rupture. The formulation $\mathrm{F}_{7}$ with 4:5 ratio of polymer: super disintegrant showed least moisture content and was found to be fragile with least folding endurance. Formulation with crospovidone and chitosan silicate conjugate in 4:1 ratio of polymer: super disintegrant having higher moisture contents, were flexible and easy to handle with good folding endurance and results were Table 3. Percentage moisture uptake values for $\mathrm{F}_{1}$ to $\mathrm{F}_{4}$ with lower proportions of chitosan silicate conjugate and crospovidone was low, suggesting that they do not absorb much moisture when placed in highly humid conditions, as these have a high percentage of moisture content and hence are stable. Percentage moisture uptake of $\mathrm{F}_{5}, \mathrm{~F}_{6}$ and $\mathrm{F}_{7}$ with higher proportions of chitosan silicate conjugate was high, suggesting that they may absorb moisture when placed in highly humid conditions, as these have less percentage of moisture content and are not very stable in highly humid environment. Maximum water vapor was transmitted across $F_{4}$ with $4: 1$ ratio of polymer:super disintegrant which has the highest permeation coefficient, while it was the least in $F_{1}$ which does not contain chitosan silicate conjugate and results were shown in Table 3 . This could be due to the formation of micro pores in $\mathrm{F}_{4}$ as seen in its scanning electron microscopic analysis (Figure 6), aided by chitosan silicate conjugate's wicking/capillary action which allows more water to be transmitted across the film while $\mathrm{F}_{1}$ not containing any super disintegrant had no micro pores detected in scanning electron microscopic analysis (Figure 6) and thus showed least water vapor transmission. The drug content within the films of respective formulation was uniform with minor deviations when analyzed by reversed phase high performance liquid chromatography and results were depicted in Table 3. Typical chromatogram of levo cetirizine di hydrochloride in Figure 7.
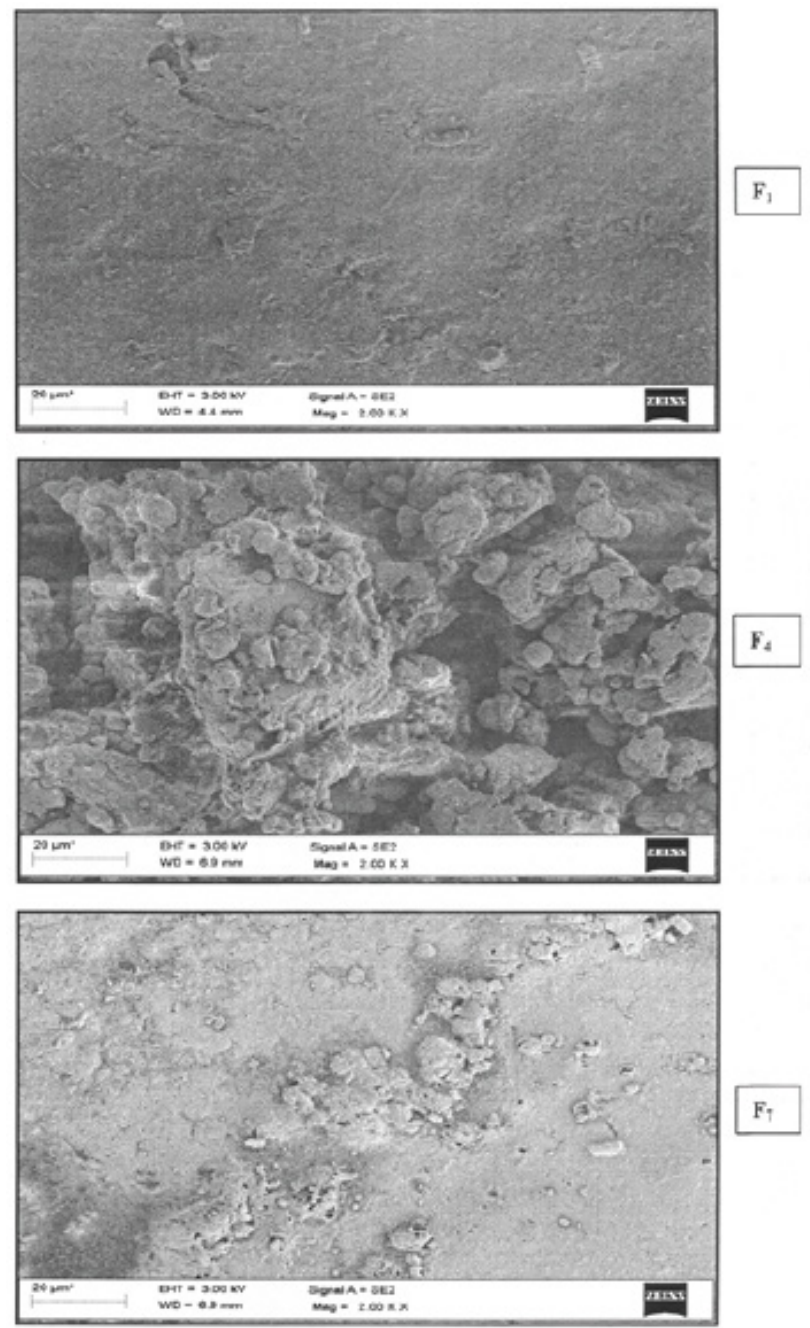

Figure 6: SEM images of formulations $F_{1}, F_{4}$ and $F_{7}$. 
Table 3: Post-Formulation Evaluation Results of Orally Fast Dissolving Films.

\begin{tabular}{|c|c|c|c|c|c|c|c|}
\hline \multirow{2}{*}{$\begin{array}{l}\text { Evaluation } \\
\text { parameters }\end{array}$} & \multicolumn{7}{|c|}{ Formulation code } \\
\hline & $F_{1}$ & $\mathbf{F}_{2}$ & $F_{3}$ & $\mathbf{F}_{4}$ & $F_{5}$ & $F_{6}$ & $F_{7}$ \\
\hline Weight $^{*}(\mathrm{~g})$ & $0.062 \pm 0.001$ & $0.062 \pm 0.001$ & $0.062 \pm 0.001$ & $0.063 \pm 0.004$ & $0.063 \pm 0.005$ & $0.064 \pm 0.005$ & $0.112 \pm 0.001$ \\
\hline Thickness ${ }^{*}(\mathrm{~mm})$ & $0.063 \pm 0.006$ & $0.086 \pm 0.006$ & $0.063 \pm 0.006$ & $0.070 \pm 0.006$ & $0.070 \pm 0.012$ & $0.070 \pm 0.006$ & $0.170 \pm 0.01$ \\
\hline Swelling index* $(\%)$ & $66.87 \pm 0.69$ & $89.26 \pm 2.90$ & $62.19 \pm 1.28$ & $96.11 \pm 0.86$ & $86.73 \pm 1.59$ & $80.37 \pm 1.27$ & $81.07 \pm 0.25$ \\
\hline Folding endurance* & $609 \pm 07.51$ & $629 \pm 26.73$ & $598 \pm 07.81$ & $528 \pm 11.93$ & $176 \pm 05.51$ & $169 \pm 01.00$ & $6 \pm 0.58$ \\
\hline $\begin{array}{l}\text { Tensile strength* }(\mathrm{N} / \\
\left.\qquad \mathrm{cm}^{2}\right)\end{array}$ & $8.51 \pm 0.10$ & $8.50 \pm 0.30$ & $9.53 \pm 0.32$ & $8.23 \pm 0.06$ & $7.77 \pm 0.45$ & $7.70 \pm 0.53$ & $1.37 \pm 0.15$ \\
\hline $\begin{array}{l}\text { Percentage elongation* } \\
(\%)\end{array}$ & $5.57 \pm 2.14$ & $9.18 \pm 2.73$ & $9.79 \pm 1.28$ & $12.59 \pm 3.52$ & $10.99 \pm 5.08$ & $5.67 \pm 0.19$ & $2.89 \pm 0.13$ \\
\hline $\begin{array}{l}\text { Percentage Moisture } \\
\text { content }^{*}(\%)\end{array}$ & $1.73 \pm 0.02$ & $1.54 \pm 0.04$ & $4.62 \pm 1.57$ & $4.29 \pm .55$ & $1.78 \pm 0.05$ & $2.03 \pm 0.84$ & $0.95 \pm 0.83$ \\
\hline $\begin{array}{l}\text { Percentage Moisture } \\
\text { uptake }^{*}(\%)\end{array}$ & $10.79 \pm 4.85$ & $16.29 \pm 3.92$ & $14.71 \pm 3.62$ & $11.51 \pm 4.49$ & $19.19 \pm 1.91$ & $25.95 \pm 6.61$ & $26.77 \pm 12.50$ \\
\hline Permeation coefficient & 1.8549 & 2.7875 & 1.9725 & 3.6525 & 2.7125 & 2.9250 & 2.8500 \\
\hline $\begin{array}{c}\text { Drug content } \\
\text { uniformity* }(\mathrm{mg})\end{array}$ & $4.81 \pm 0.002$ & $4.81 \pm 0.001$ & $4.82 \pm 0.005$ & $4.71 \pm 0.001$ & $4.82 \pm 0.016$ & $4.63 \pm 0.005$ & $4.72 \pm 0.002$ \\
\hline $\begin{array}{l}\text { In vitro disintegration } \\
\text { time }^{*}(\mathrm{~s})\end{array}$ & $54.33 \pm 1.528$ & $25.00 \pm 1.000$ & $53.33 \pm 0.577$ & $28.67 \pm 1.155$ & $33.33 \pm 0.577$ & $35.33 \pm 1.155$ & $41.00 \pm 1.732$ \\
\hline $\begin{array}{l}\text { Percentage CDR } \\
\text { after } 5 \text { min for in vitro } \\
\text { dissolution study (\%) }\end{array}$ & 92.27 & 95.39 & 92.39 & 95.36 & 93.39 & 93.55 & 94.36 \\
\hline $\begin{array}{l}\text { Percentage CDR } \\
\text { after } 9 \text { min for in vitro } \\
\text { permeation study }(\%)\end{array}$ & 88.62 & 95.21 & 91.53 & 94.01 & 92.39 & 92.13 & 91.94 \\
\hline
\end{tabular}

The formulation $\mathrm{F}_{4}$ consists of chitosan silicate conjugate with 4:1 ratio of polymer: super disintegrant showed the least disintegration time as compared to other formulations consists of chitosan silicate conjugate as Table 3. This is attributed to the microcrystalline nature of chitosan silicate conjugate, wicking/capillary property of chitosan silicate conjugate aided by lesser viscosity of chitosan silicate conjugate compared to chitosan that facilitate higher influx of water into the formulation and formation of micro pores to the maximum extent in the formulation $\mathrm{F}_{4}$. The maximum water vapor permeation coefficient for these films confirms the formation of micro pores to the maximum extent in $\mathrm{F}_{4}$. Swelling index for $\mathrm{F}_{4}$ was more than the other formulations also suggested the presence of more micro pores causing more swelling of these films. The disintegration time for the formulation $\mathrm{F}_{4}$ consists of chitosan silicate conjugate did not significantly differ from that of the films containing crospovidone, a commercially used super disintegrant, in the same proportion, attributes to the effective use of chitosan silicate conjugate as a super disintegrating agent in films.
All the formulations were found to release the drug in five min, when subjected to in vitro dissolution study and permeate the drug in nine min, when subjected to in vitro permeation study. Among the formulations consists of chitosan silicate conjugate, $\mathrm{F}_{4}$ with 4:1 ratio of polymer: super disintegrant showed maximum drug release and permeation due to the super disintegrating property of chitosan silicate conjugate responsible for the faster disintegration and hence faster drug release

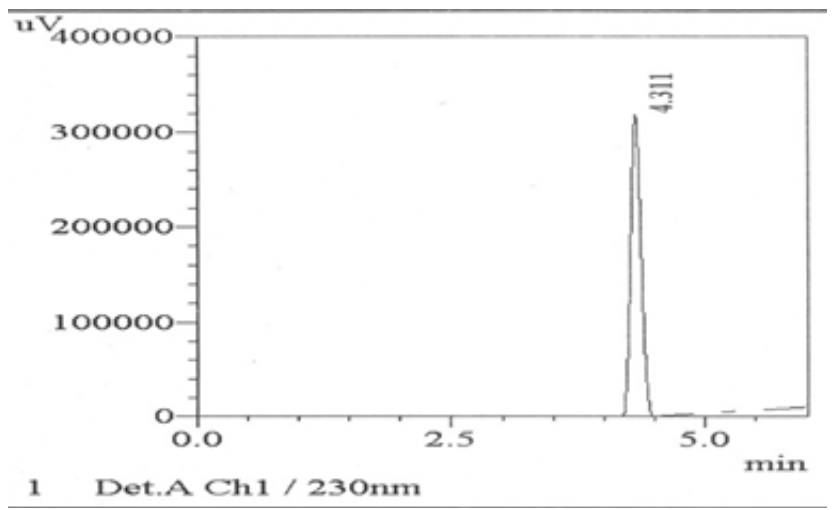

Figure 7: Typical chromatogram of levocetirizine dihydrochloride. 


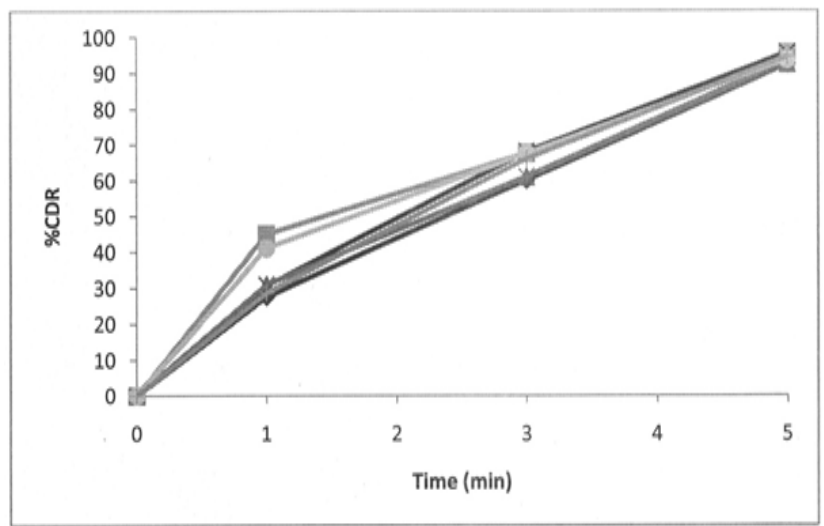

Figure 8: \%CDR v/s time plot for in vitro dissolution study; $\rightarrow F 1, \rightarrow F 2, \rightarrow F 3, \multimap F 4, \rightarrow F 5, \multimap F 6, \rightarrow F 7$.

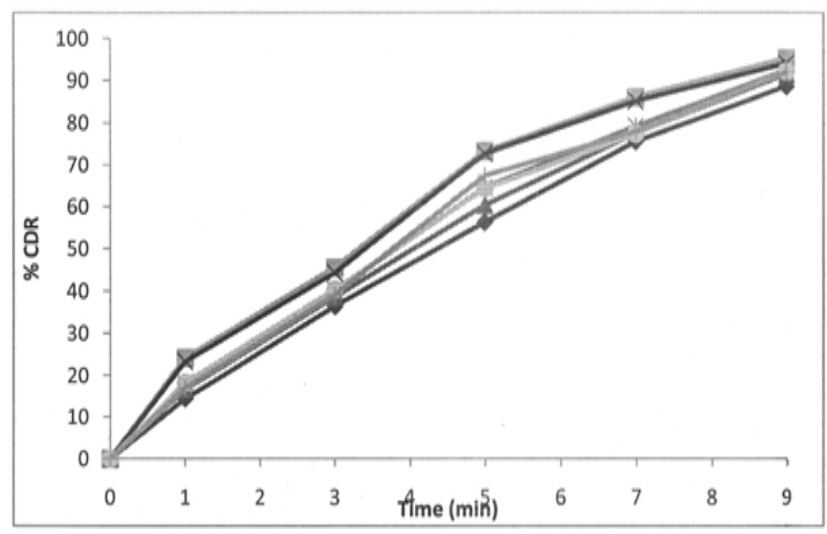

Figure 9: \%CDR v/s time plot for in vitro permeation study; $\rightarrow F 1, \rightarrow F 2, \rightarrow F 3, \multimap F 4, \rightarrow F 5, \multimap F 6, \rightarrow F 7$.

Table 4: Accelerated Stability Studies Data For The
Formulation F4.
\begin{tabular}{|c|c|c|} 
SI.No & Evaluation parameters & Formulation F $_{4}$ \\
\hline 1 & $\begin{array}{c}\text { Drug content of } 6.25 \mathrm{~cm}^{2} \text { films } \\
(\mathrm{mg})\end{array}$ & 4.7063 \\
\hline 2 & In vitro disintegration time* $(\mathrm{s})$ & $28.33 \pm 1.155$ \\
\hline 3 & $\begin{array}{c}\text { Percentage CDR after } 5 \text { min for in } \\
\text { vitro dissolution study }(\%)\end{array}$ & 94.99 \\
\hline
\end{tabular}

and permeation in these films as shown in Table 3. The percentage CDR v/s time plots for in vitro dissolution and in vitro permeation study is shown in (Figure 8 and 9) respectively.

The topographical study of $\mathrm{F}_{4}$ with $4: 1$ ratio of polymer: super disintegrant showed the presence of micro pores and microcrystalline structures of chitosan silicate conjugate in the film. The micro crystalinity of chitosan silicate conjugate was confirmed by X-ray diffraction analysis and folding endurance value of the film. Formulation $F_{1}$ which does not contain chitosan silicate conjugate did not show the presence of micro pores, this could be the reason for the film to have less water vapor permeation as compared to the films containing chitosan silicate conjugate. As the proportions of chitosan silicate conjugate increased in the films, the presence of micro pores also decreased and the same was observed in the scanning electron microscopic image of $\mathrm{F}_{7}$ with 4:5 ratio of polymer: super disintegrant.

The films of formulation $\mathrm{F}_{4}$ with 4:1 ratio of polymer: super disintegrant chitosan silicate conjugate showed no significant differences in their disintegration time, drug content and drug release on dissolution as depicted in Table 4 and hence was concluded to be stable after 60 days of storage at $40 \pm 2^{\circ} \mathrm{C} 75 \pm 5 \%$ relative humidity.

\section{CONCLUSION}

The present research study included the synthesis of chitosan silicate conjugate along with its characterization primarily by charring point, viscosity and wicking property determinations and confirmed by Fourier transforms infrared spectroscopy, differential scanning calorimetric and X-ray powder diffraction analysis.

The formulations consists of different proportions of chitosan silicate conjugate and crospovidone as super disintegrants and those without super disintegrants, were prepared and subjected to various post formulation evaluation and were found to be uniform in weight, thickness and drug content.

Among all the formulations consists of chitosan silicate conjugate, $\mathrm{F}_{4}$ with $4: 1$ ratio of polymer: super disintegrant showed least disintegration time. This could be due to the microcrystalline nature, presence of more micro pores and wicking/capillary property of chitosan silicate conjugate aided by its lower viscosity and these are the reasons for the super disintegrant property of chitosan silicate conjugate. As the proportions of chitosan silicate conjugate increased in the formulation, disintegration time also increased, which could be due to the absence of micro pores in the films consisting of higher proportions of chitosan silicate conjugate. The films consists of crospovidone, has showed lower disintegration time than that of $\mathrm{F}_{4}$ and this difference is not significant.

The in vitro dissolution and the in vitro permeation studies also suggested that from the formulation $\mathrm{F}_{4}$, maximum drug was released within five minutes and maximum drug permeated within nine minutes, due to the super disintegrant property of chitosan silicate conjugate. Formulation $\mathrm{F}_{4}$ was subjected to stability study for 60 days and was found to be stable with respect to its disintegration time, drug content and in vitro dissolution. 
Hence this research study concluded that the chitosan silicate conjugate can be used as a super disintegrant in films.

\section{ACKNOWLEDGEMENT}

The authors are thankful to Karnataka Antibiotics and Pharmaceuticals Ltd, Bengaluru, Karnataka for providing gift samples of Levo cetirizine dihydorchloride and aspartame, Strides Arco Laboratories Ltd, Bengaluru, Karnataka for providing gift sample of Crospovidone. The authors express gratitude to the Principal, Government Collage of Pharmacy, Bengaluru, Karnataka for providing necessary facilities to carry out the research.

\section{CONFLICT OF INTEREST}

The authors declare no conflict of interest.

\section{ABBREVIATIONS}

OFDF: Orally Fast Dissolving Oral Films; IgE: Immuniglobin E; CSC: Chitosan Silicate Conjugate; FT-IR: Fourier Transform Infrared Spectroscopy; DSC: Differential Scanning Calorimetry; XRD: X-Ray Diffraction; RP-HPLC: Reverse Phase High Performance Liquid Chromatography; \%CDR: Percentage Cumulative Drug Release; rpm: Rotation Per Minute; SEM: Scanning Electron Microscopic; ICH: International Conference on Harmonization; UV: Ultra Violet.

\section{REFERENCES}

1. Chaudhary H, Gauri S, Rathee P, Kumar V. Development and optimization of fast dissolving oro-dispersible films of granisetron hydrochloride using BoxBehnken statistical design. Bull Fac Pharm Cairo Univ. 2015;51(2):193-201.
2. Bhyan B, Jangra S, Kaur M, Singh H. Orally fast dissolving films: Innovations in formulations and technology. International Journal of Pharmaceutical Sciences Review and Research. 2011;9(2):50-7.

3. Patil SL, Mahaparale PR, Shivniker MA, Tiwari SS, Pawar KV, Sane PN. Fast dissolving oral films: An innovative drug delivery systems. International Journal of Research and Review in Pharmacy and Applied Science. 2012;2(3):482-96

4. Environmental Allergies: Diagnosis. NIAID. May 12, 2015. Archived from the original on June 17, 2015.

5. Prabhu P, Malli R, Koland M, Vijaynarayana K, D'Souza U, Harish NM, et al. Formulation and evaluation of fast dissolving films of levocitirizine dihydrochloride. Int J Pharm Investig. 2011;1(2):99-104.

6. Pandis C, Madeira S, Matos J, Kyritsis A, Mano JF, Ribelles JLG. Chitosansilica hybrid porous membranes. Mater Sci Eng C. 2014;42:553-61.

7. El-Barghouthi M, Rashid AEI, Al-Remawi M, Badwan A. A novel super disintegrating agent made from physically modified chitosan with silicon dioxide. Drug Dev Ind Pharm. 2008;34:373-83.

8. Satheeshababu BK, Shivkumar KL. Synthesis of conjugated chitosan and its effects on drug permeation from transdermal patches. Indian J Pharm Sci. 2013;75(2):162-70.

9. El-hefian EA, Elgannoudi ES, Mainal A, Yahaya AH. Characterization of chitosan in acetic acid: Rheological and thermal studies. Turk $\mathrm{J}$ Chem. 2009;34(1):47-56.

10. Grigg TR, Liewehr FR, Rattan WR, Buxton TB, McPherson JC. Effect of wicking behavior of multi filament sutures. J Endodont. 2004;30(9):649-52.

11. Xu LL, Shi LL, Cao QR, Xu WJ, Cao Y, Zhu XY, et al. Formulation and in vitro characterization of novel sildenafil citrate-loaded polyvinyl alcoholpolyethylene glycol graft copolymer-based orally dissolving films. Int J Pharm. 2014;473(1-2):398-406.

12. Choudhary DR, Patel VA, Chhalotiya UK, Patel HV, KundawalaAJ. Formulation and evaluation of fast dissolving film of levocetirizinedihydrochloride using different grades of methocel. J Pharm Res. 2011;4(9):2919-24.

13. Maheswari KM, Devineni PK, Deekonda S, Shaik S, Uppala NP, Nalluri BN. Development and Evaluation of Mouth Dissolving Films of Amlodipine Besylate for Enhanced Therapeutic Efficacy. J Pharma. 2014;4:1-10.

14. Raja T, Rao AL. Development and validation of a reversed phase HPLC method for simultaneous determination of levocetirizine and montelukast sodium in tablet dosage form. Int J Res Pharm Chem. 2012;2(4):1057-63.

15. Naaz A, Vani R. Simultaneous estimation of montelukast and levocetirizine in its bulk and liquid dosage forms by RP-HPLC. Indo Am J Pharm Res. 2015;5:3338-47

\section{SUMMARY}

The goal of the present research study was to evaluate chitosan silicate conjugate as super disintegrant and compare its disintegration capacity with commercially available super disintegrant. The study included preparation and characterization of chitosan silicate conjugate. The characterization was done by determining physical constituents and application of various analytical tools. The conjugate was included in formulation of orally fast dissolving films of levo cetirizine di hydrochloride as a super disintegrant to evaluate its super disintegration property and compared with commercially available super disintegrant crospovidone. The results of present study revealed that prepared conjugate was successfully characterized, both drug and excipients were compatible, prepared films were evaluated for various parameters and found that films were suitably formulated. The study results were attributed that prepared chitosan silicate conjugate has super disintegration property and its disintegration capacity was high than commercially available disintegrant crospovidone. 
PICTORIAL ABSTRACT

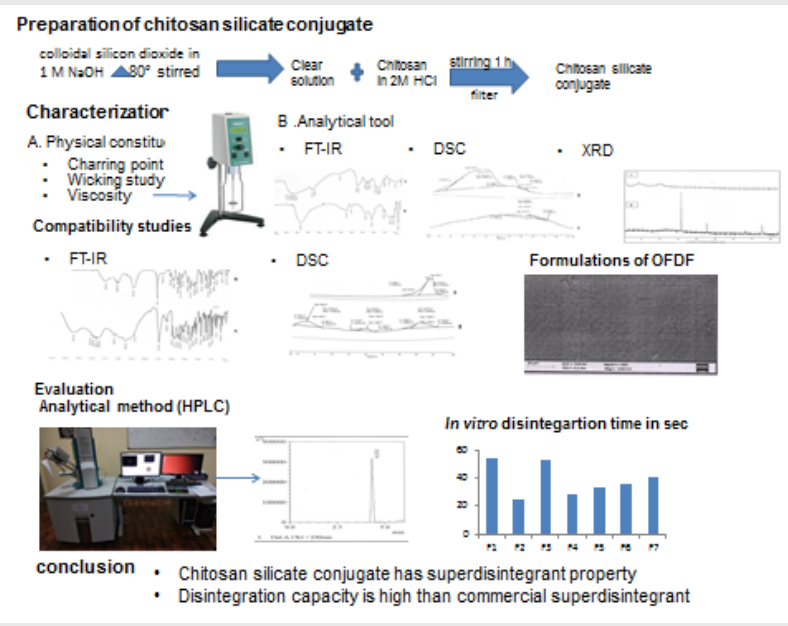

\section{About Authors}

Prof. Satheesha Babu Birur Kotappa, M. Pharm, Ph.D: Presently serving as a Professor at Department of Pharmaceutics, Government College of Pharmacy, \#2, P Kalinga Rao Road, Subbaiah Circle, Bengaluru, Karnataka, India. His research area is novel drug delivery systems.

Mis. Podamala Rama Smriti, M. Pharm currently she is an Associate Clinical Publisher at M/S Nova Nordic Service Centre india Private Ltd, Bengaluru, Karnataka.

Cite this article: Babu BKS, Smriti PR. Preparation and Characterization of Chitosan Silicate Conjugate: It's Role as a Super Disintegrant in Orally Fast Dissolving Films. Indian J of Pharmaceutical Education and Research. $2021 ; 55(2 s):$ s385-s395. 